\title{
EUSÉBIO DE SOUSA E O PROCESSO DE CRIAÇÃO DO ARQUIVO PÚBLICO DO ESTADO DO CEARÁ EM 1932 ${ }^{1}$

\author{
EUSÉBIO DE SOUSA AND THE CREATION PROCESS OF
} THE PUBLIC ARCHIVE OF THE STATE OF CEARÁ IN 1932
}

\author{
Ana Carla Sabino Fernandes*
}

\begin{abstract}
Resumo: Este artigo estabelece um diálogo com as orientações históricas, políticas e arquivísticas de Eusébio Néri Alves de Sousa (1883-1947), que foi advogado, juiz, jornalista e historiador, sócio efetivo do Instituto Histórico, Geográfico e Antropológico do Ceará (Instituto do Ceará, fundado em 1887), diretor do Arquivo Público do Estado do Ceará e também do Museu Histórico do Ceará entre 1932 e 1942. Destaco o discurso histórico de Sousa em vários livros, documentos oficiais, artigos que ele escreveu e em produções históricas em que é referência, bem como os seus feitos e os rumos impetrados ao/no Arquivo Público, que dataram e legalizaram a tradição arquivística e o Arquivo no Ceará a partir de 1932 (e não no século XIX), sob a influência dos estudos históricos do Instituto do Ceará e dos paradigmas que regiam os Arquivos Públicos no século XX enquanto "lugar" da memória, do documento histórico e da escrita da história, pautado na ideia de que a arquivística era uma ciência auxiliar da história.
\end{abstract}

Palavras-chave: Eusébio de Sousa. Arquivo Público do Estado do Ceará. Memória Arquivística.

\footnotetext{
* Professora na Universidade Federal do Ceará (UFC). E-mail: anacarlasabino@ig.com.br
} 


\begin{abstract}
This article establishes an intense dialogue with the historical, political and archival guidelines of Eusébio Néri Alves de Sousa (18831947), who was a lawyer, judge, journalist and historian, effective member of the Anthropological, Geographical and Historical Institute of Ceará (Ceará Institute, founded in 1887), director of the Public Archives of the State of Ceará and also of the Historical Museum of Ceará from 1932 to 1942. I highlight Sousa's historical discourse in several books, official documents, articles he wrote and historical productions, as well as his achievements and directions found in the Public Archive, which dated and legalized the archival tradition and Archive in Ceará as from 1932 (and not in the XIX century), under the influence of historical studies of the Institute of Ceará and paradigms that ruled the Public Archives in the XX century as a "place" of the memory, the historical document, and of history writing, based on the idea that the Archival memory was an auxiliary science of History.
\end{abstract}

Keywords: Eusébio de Sousa. Public Archive of the State of Ceará. Archival Memory.

Viva 0 arquivo morto!

\title{
HISTÓRICO DA CRIAÇÃO DO ARQUIVO
}

O Arquivo Público do Estado foi restabelecido pelo decreto $\mathrm{n}^{\circ} 479$, de 3 de fevereiro do corrente ano. Restabelecido, não é bem o termo. Tal repartição jamais existiu, embora criada pelo art. $2^{\circ}$, da lei $\mathrm{n}^{\circ} 1.371$, de 6 de setembro de 1916 , instituída pelo paragrafo único, do art. $8^{\circ}$ da lei $\mathrm{n}^{\circ}$ 1.872 , de 24 de setembro de 1921 , que a revogou como dependência administrativa da Secretaria dos Negócios do Interior e da Justiça [...].

Já anteriormente, no antigo regimen [sic], em virtude do paragrafo 23 do art. $3^{\circ}$ da lei $n^{\circ} 1.186$, de 8 de setembro de 1865 , e paragrafo 21 do art. $3^{\circ}$ da lei $\mathrm{n}^{\circ} 1.222$, de 20 de dezembro de 1866 (leis de meio) foi criada essa repartição como dependência da Biblioteca Provincial, instalada a 25 de março de 1867.

Não há, entretanto, notícia da eficiência dêsse [sic] Arquivo nos dias atuais, não passando a sua criação de uma coisa morta, tendo apenas a sua existência no espirito da lei que o criou. [...]

O Arquivo Público, portanto, nunca teve vida no Ceará. Nem ao menos uma existência efémera. [...]. ${ }^{2}$ 
O Arquivo Público do Estado do Ceará é fonte e objeto dos estudos e pesquisas históricas que originaram este artigo. Para tanto, tomo o desafio de escrever sobre uma instituição que foi "enterrada viva" várias vezes, sendo, quando oportuno, "ressuscitada".

Eusébio Néri Alves de Sousa ${ }^{3}$, diretor do Arquivo Público do Ceará (atual arquivo permanente do estado) entre 1932 e 1942, nomeado em 01 de junho de 1932, assim atestou inúmeras vezes - é o caso do trecho do Relatório citado acima - que o arquivo no Ceará era "coisa morta", que nunca teve vida, nem mesmo efêmera, criado, de fato e de direito, em 3 de fevereiro de 1932 pelo Decreto $n^{\circ} 479$, e jamais em 1865, 1866, 1916 e 1921, como rezam as leis e decretos anteriores ao ano de 1932.

Ao falar da falência do arquivo antes de 1932 e do surgimento de um "novo" arquivo a partir dessa data, Sousa estabelece uma relação conflituosa e discrepante entre o que seria a história da instituição do arquivo no Ceará e o que convenciono chamar de "memória arquivística", com base nas análises historiográficas sobre história e memória de Pierre Nora e Paul Ricoeur. A citação abaixo é uma apropriação de Ricoeur a partir do artigo de Nora, "Entre memória e história. A problemática dos lugares”, para tratar do momento em que a memória é apreendida pela história por meio do arquivo e do arquivamento dos registros escritos, ou seja, da "memória arquivística":

Terceiro tema: da ruptura entre história e memória, da perda assumida da história-memória, emerge uma nova figura, a da "memória apreendida pela história". Três traços dessa nova figura são desenhados. Em primeiro lugar, o reinado do arquivo. Essa nova memória é uma "memória arquivística", uma "memória de papel", diria Leibniz. Reconhecemos nessa "obsessão do arquivo" a grande mutação exagerada do mito de Fedro, que trata da invenção da escrita. Vitória do escriturário no próprio cerne do memorial. [...] O sentimento da perda, como mito platônico, torna-se a contrapartida dessa institucionalização da memória. "Produzir arquivo é o imperativo da época". É um pouco em tom de imprecação que Nora exclama: “Arquivai, arquivai, sempre restará algo!" O arquivo "não é mais o saldo mais ou menos intencional de uma memória vivida, mas, a secreção voluntária e organizada de uma memória perdida". "Terrorismo da memória historicizada".

A história do arquivo, nestes termos, é escrita através da crônica histórica das datas, fatos, dos espaços públicos, grupos de pessoas, indivíduos, atos legais e feitos da instituição apresentados como um todo irrefutável, atendendo aos fins da organização política da memória, o que definirá a concepção do arquivo como instrumento do poder público perante a sociedade cearense em 
geral, inserido no contexto das instituições públicas do Brasil e espaço do conhecimento das ciências sociais, humanas, jurídicas e administrativas.

As dependências do "novo" arquivo, apresentado por Eusébio de Sousa, e a associação a ele, servirão como moldura para os documentos repatriados nesse espaço, agora em plena harmonia com os retratos dos seus respectivos heróis - os presidentes de província e governadores estaduais, "autores" dos papéis cearenses que não poderiam ser renegados pelo esquecimento da administração pública e, muito menos, dispensados da lembrança do que viria a ser o arquivo:

Sem que me torne importuno, ou mesmo ousado no alvitre a sugerir, eu lembraria ao Exmo. Snr. Secretário dos Negocios do Interior e da Justiça a conveniência, altamente significativa, da transferência da galeria de retratos ora existente na respectiva sala de trabalhos, para o Arquivo, a qual servirá de início promissor da que, futuramente se não me entibiar a forte dóse de bôa vontade de que me acho possuído, em dias não remotos, sem dúvida, extasiará os olhos dos visitantes, na contemplação dos vultos dos prohomens que ocuparam posição de relevo na vida pública e ainda por atos e ações dignificantes [que] elevaram o nome da terra que lhes viu nascer.

Essa galeria -aludo á dos antigos presidentes da província e do Estado- no local em que ora se encontra, serve apenas de simples ornamento, dada a natureza especial do salão, isolado do público, como casa do trabalho que é, enquanto que no Arquivo Público terá maior apreço e veneração da geração contemporânea e dos porvindouros, evocando as suas figuras gloriosas e os feitos da história nacional e do Estado. $^{5}$

A intenção de Sousa ao montar/reproduzir o cenário do ato documental dos vultos cearenses com, por exemplo, pinturas e fotos dos ex-presidentes da província e ex-governadores do Ceará na Sala do Conselheiro Tristão Alencar Araripe e na Sala Antonio Bezerra, pertencente ao arquivo (ver Figuras n. $1 \mathrm{e}$ 2), foi demonstrar que os documentos assinados por esses homens do poder se tornaram oficiais e, no futuro próximo, figurariam como documentos históricos para a escrita da história do Ceará. 
Figura 1 - Arquivo Público do Estado do Ceará em 1932

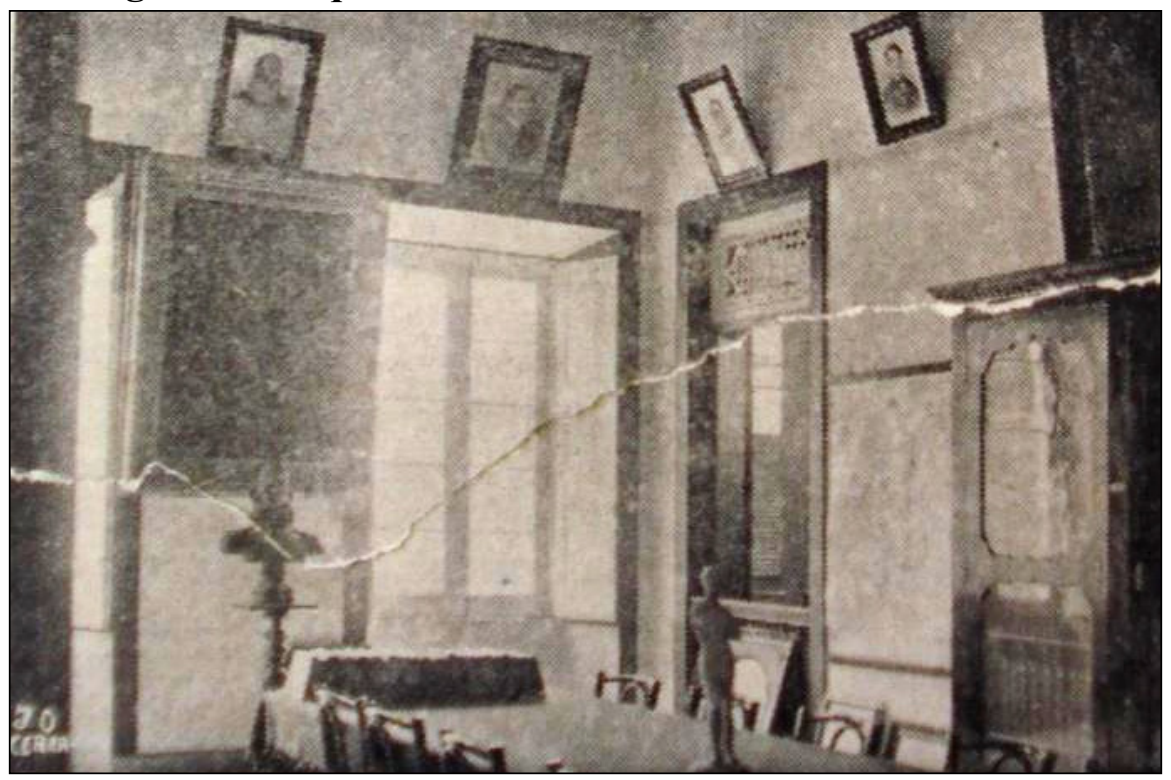

Térreo do Palácio da Luz, que hoje abriga a Academia Cearense de Letras (Praça dos Leões, centro de Fortaleza). Sala Conselheiro Tristão Alencar Araripe e sala de consultas do arquivo. Fonte: REPUBLICA DOS ESTADOS UNIDOS DO BRASIL, $1936 .{ }^{6}$

Figura 2 - Sala Antonio Bezerra, seção Museu Histórico do Arquivo Público em 1932

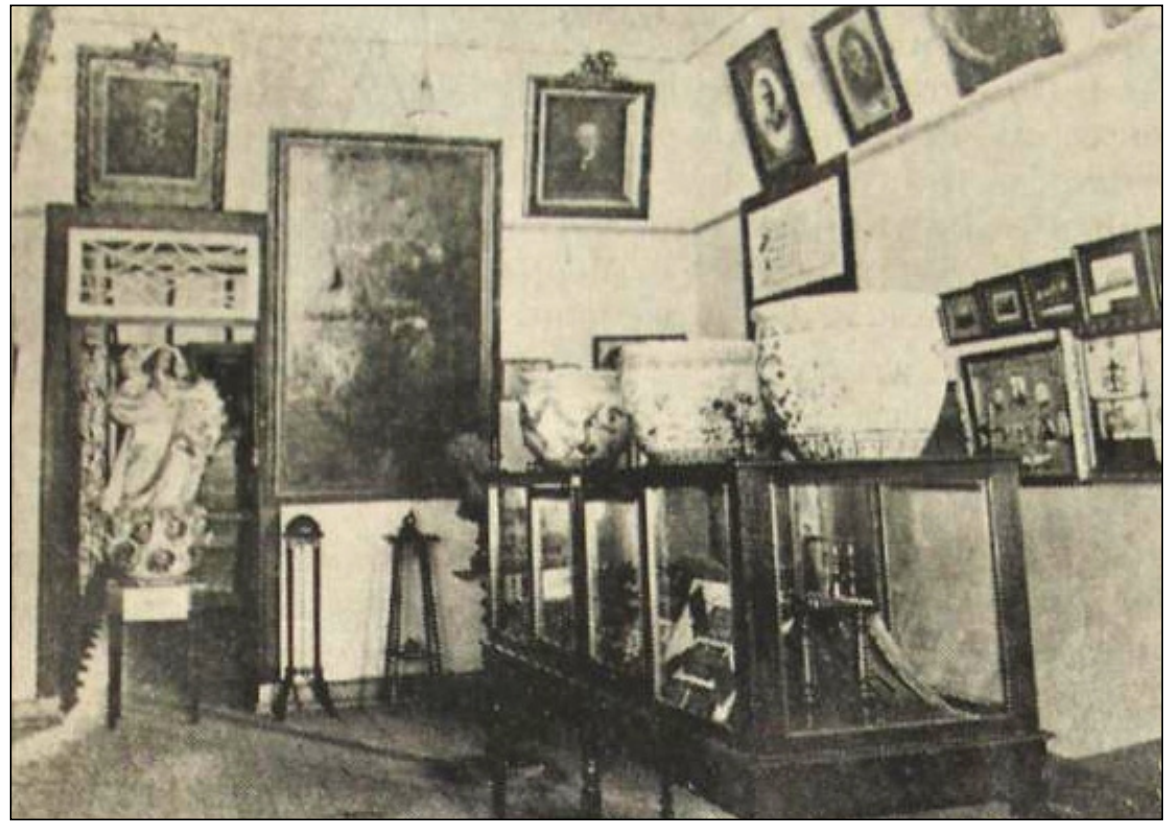

Fonte: REPUBLICA DOS ESTADOS UNIDOS DO BRASIL, 1936. ${ }^{7}$ 
O cerne dessa história acontece, portanto, entre os anos de 1932 e 1942, quando Sousa, o secretario dos negócios do interior e da justiça, o interventor federal no Ceará, com os demais funcionários do Arquivo, fomentam, produzem, guardam e conservam intensa documentação comprobatória do ciclo gerador do arquivo no estado do Ceará, a exemplo dos relatórios suscitados anteriormente.

E será a partir da acumulação arquivística de um conjunto documental administrativo que, nos tempos de escrita desse artigo, o Arquivo Público do Estado do Ceará (APEC) dar-se-á a ler. Oferecendo ao pesquisador dois índices bem sedutores aos olhos dos historiadores, chamados: "Índice de localização do grupo arquivo público e museu histórico. Data crônica: 1932-1958. Ala 03, Estante 04" e "Fundo: Interior e Justiça; Série: Arquivo Público, Biblioteca Pública e Museu Histórico do Ceará. Data-limite: 1878-1944”. ${ }^{8}$

Adianto que, no caso dos documentos a respeito das "cousas" do arquivo entre 1878-1944, o fundo é quase absolutamente "falso", proveniente ou não do próprio arquivo entre o final do século XIX e início do século XX. Isto porque o arquivo público da província do Ceará, criado por decreto em 1865, como anexo da biblioteca pública provincial, até fins do século XIX não tinha composto os "seus" papéis (acervo), pois, o arquivo da secretaria do governo da província, em vigor desde 1836, continuava como sede dos documentos de toda ordem e valor. Ao contrário dos documentos do/sobre o arquivo (do seu funcionamento e desenvolvimento) nos anos 1930 e 1940, que foram intencionalmente arranjados e constam no "Índice de localização do grupo arquivo público e museu histórico”. Cito as espécies documentais deste índice: decretos e resoluções, ofícios expedidos e recebidos, atas de instalação em seu novo prédio e livros com impressões de visitantes, catálogo geral do acervo, registro de visita, frequência de funcionário, pedido de férias, entrega de certidões e registro de certidões.

Essa é uma das fontes primordiais para o estudo a contrapelo (não oposto) das impressões de Sousa sobre o arquivo, pois creio que tomei consciência da historicidade do arquivo no Ceará, ao ponto de pensar sobre a narrativa de reconstrução do passado deste arquivo e acerca da organização da sua memória social. ${ }^{9}$

Os indícios documentais oferecidos para a pesquisa e escrita da história do Arquivo no Ceará são, portanto, do tipo oficial, o que difere do conceito de documento público ou histórico, ou seja, foram produzidos para uso restrito e circunscrito à administração pública e acumulados como documentos de/ do arquivo. Os documentos que interessariam aos estudos dos historiadores, pessoas devidamente imbuídas da prática historiadora (e não a qualquer tipo de público), e tinham valor histórico na concepção de Sousa eram, por exemplo, os documentos sobre a presença dos holandeses e portugueses no "Siara Grande" e das antigas vilas do Ceará, século XVII e XVIII. 
Assim, a ideia de documento público na década de 1930 e 1940 está mais relacionada aos registros/documentos cartoriais e eclesiásticos, à busca pela fé pública (em especial a fé pública notarial), documentos para uso legal e moral do público e sob o controle da ordem pública, no que diz respeito à identidade e à propriedade civil e religiosa dos cidadãos, do que pela questão entorno dos documentos do poder executivo como patrimônio histórico, debate em pauta nestes anos, como objeto de pertencimento da sociedade cearense.

A história do arquivo, seguindo a ordem de produção, formação e disponibilização do seu acervo, começaria e terminaria na busca cronológica e referencial que parte da negação das experiências arquivísticas no Ceará no século XIX, segue pelo dinamismo da invenção criadora, até chegar à inércia da consolidação almejada, em 1932. Para isso, tem-se à mão o conjunto documental composto por papéis rubricados, selados e timbrados, cujo remetente, destinatário e produtor foi, na pessoa de seu diretor, o arquivo, que se faz arbitrariamente testemunha de si.

O caráter isoladamente institucional do arquivo dá sustentação ao senso comum, "histórico" de que falar do arquivo público estadual do Ceará é remeterse unicamente a Eusébio de Sousa. O arquivo quando passa pelo caminho dos historiadores cearenses, pelas entrelinhas de uma escrita despretensiosa, transpõe-se, ainda, como texto invisível, dissociado do documento de arquivo, sua fonte, mas, nem sempre objeto de estudo.

Ao se analisar com afinco essa documentação (o "Índice de localização do grupo arquivo público e museu histórico"), por suas entrelinhas e fora delas, tem-se três impressões marcantes para que seja possível travar uma discussão hermenêutica sobre a persistência de certas súmulas narrativas em torno da história do arquivo no Ceará, as sínteses que os historiadores e o público em geral reescrevem a partir do tal índice, bem como as implicações e significados desses discursos.

O primeiro rastro prospectado da documentação é o dado de que Eusébio de Sousa foi o mentor intelectual, técnico e político do arquivo público do Ceará, tornando-se, portanto, diretor desta instituição entre 1932-1942. Segundo, que o arquivo foi "restabelecido" pelo decreto oficial n ${ }^{\circ} 479$, regulado pelo decreto $\mathrm{n}^{\circ}$ 643, em fevereiro e junho de 1932, respectivamente. Mas, de fato, e por que não de direito, foi "criado" por Sousa durante os seis primeiros meses em que esteve na direção do arquivo, como consta em seu primeiro relatório de atividades, junho a dezembro de 1932. Por fim, que o arquivo surge em 1932 e se constitui até 1958, pois esta é data crônica da única ferramenta de pesquisa sobre o arquivo disponível na sala dos investigadores do Arquivo Público do Estado do Ceará.

Contudo, relacionado a este entendimento expressamente dizível e direcionado por Sousa sobre "uma história do arquivo do Ceará", inclui-se o tema da "memória arquivística", que põe esta história do lado avesso, ou seja, 
não nega a trajetória de sucessos, fracassos e "mortes" de um ou dos vários arquivos, desde o início do século XIX, em terra cearense. Pelo contrário, aproxima-a do que é mais cotidiano e salutar no interior de um arquivo, ou seja, o seu material, o material de arquivo $^{10}$, o documento, a criação de suportes, métodos, práticas, teorias, lugares, leis, profissões e ofícios para a preservação e o fazer da memória dos indivíduos e das entidades sociais registradas cautelosamente, melhor dizendo, diplomaticamente, em documentos que trazem, diante desta ordem, um enredo histórico:

Tudo o que chamamos hoje de memória não é, portanto, memória, mas já história. [...] É antes de tudo, uma memória, diferentemente da outra arquivística. Ela se apoia inteiramente sobre o que há de mais preciso no traço, mais material no vestígio, mais concreto no registro, mais visível na imagem. O movimento que começou com a escrita termina na alta fidelidade e na fita magnética. Menos a memória é vivida do interior, mais ela tem necessidade de suportes exteriores e de referenciais tangíveis de uma existência que só vive através delas. Daí a obsessão pelo arquivo que marca o contemporâneo e que afeta, ao mesmo tempo, a preservação integral de todo o presente e a preservação integral de todo passado. $\mathrm{O}$ sentimento de um desaparecimento rápido e definitivo combinase à preocupação com exato significado do presente $\mathrm{e}$ com a incerteza do futuro para dar ao mais modesto dos vestígios, ao mais humilde testemunho a dignidade virtual do memorável. ${ }^{11}$

Ao abnegar os traços que definem a memória arquivística, Sousa nos provoca. É como se dissesse que o Arquivo "nasceu sem berço", filho de "pais" sem nome e tradição, em circunstâncias sociais e legais fracassadas e que só a partir das suas empreitadas administrativas, jurídicas e como intelectual da história, cuja ação estava sendo experimentada entre 1928 e1933, quando se tornou sócio efetivo, depois membro da diretoria do Instituto Histórico, Geográfico e Antropológico do Ceará (Instituto do Ceará) e integrante da comissão de redação da Revista do Instituto do Ceará, criada em 1887, com a inauguração do próprio Instituto.

$\mathrm{O}$ arquivo no Ceará, com Sousa, surgiria novidadeiro. Uma nova "espécie" da administração pública reconhecida a priori pelas instâncias do poder público cearense, por uma sociedade espectadora, em harmonia com os fins do Instituto do Ceará, supostamente ávida pelo conteúdo histórico, administrativo e geográfico inédito a ser revelado pelos documentos devidamente conservados e acessíveis para consulta.

Desse modo, o arquivo foi um instrumento de poder do aludido gestor usado como e para a criação de um referencial de gestão política, de serviço 
público, ferramenta governamental, fonte histórica e da técnica arquivística. Um arquivo sem interlocução com tempos passados, sem "vida própria ou vida social", ou seja, não é entendido como fruto e a despeito da ação humana mediada, especialmente a partir do século XIX, pelos documentos escritos. O Arquivo é sujeitado às buscas do tipo "paleontológicas" que marcaram o gênero fatídico da escrita da história do Ceará nos anos 1930.

Ou seja, o método de trabalho positivista e as intenções desbravadoras dos estudos naturalistas de intelectuais da estampa de Thomaz Pompeu Sobrinho (1880-1967), presidente do Instituto do Ceará entre 1938 e 1967, marcaram a caça por documentos para a história do Ceará em diversos lugares e continuaram sendo adotados na sala de consultas do arquivo, visto que os consulentes não tinham como saber de forma mais ou menos precisa quais e quantos documentos o arquivo possuía, pois Sousa desconsiderou os inventários de documentos arquivados no século XIX e só em 1933 irá dispor o "Índice alfabético e remissivo das Datas de Sesmarias do Estado do Ceará" e em 1934 o primeiro catálogo de documentos. ${ }^{12}$

Em 1939 Thomaz Pompeu Sobrinho publicou o artigo "Tapuias do Nordeste" na Revista do Instituto do Ceará, um dos textos pioneiros sobre a relação entre o estado do Ceará e a região Nordeste e acerca da contribuição étnica e linguística dos indígenas "nordestinos" para a pré-história do Ceará e dos cearenses. Para tanto, discorre sobre o tema da pesquisa e os "desenterramentos" de documentos nos arquivos, incluindo o arquivo público do Ceará, quase sempre infrutíferos.

Os dados da questão que atualmente chegam as nossas mãos se mostram desanimadoramente deficientes... Constam ordinariamente de relatórios, cartas e crônicas mal apanhadas e viciosamente registradas em vista do espirito apaixonadamente político e religioso do tempo. Sem nenhum interesse de ordem cientifica, estes documentos que se vão desenterrando dos velhos arquivos revelam quando muito trechos de verdades que cumpre surpreender com paciência e perspicácia de entre um acervo enorme de cousas inúteis ou de somenos interesse para o caso. [...] No Ceará, consultam-se com relativo proveito as coleções do Museu Rocha, as coleções do Autor, do Dr. Baltar e do Arquivo Público. [...].13

O documento no arquivo fincava a certeza de que primeiro era preciso cortejar o arquivo, melhor, o seu "fiel depositário", para em seguida ter acesso aos documentos inéditos.

Capítulo III. Da consulta de documentos. [...]. Art.30. Ninguém será admitido a consulta, sem que, antes e por 
escrito, indique, em livro próprio, de modo claro, minucioso e explicito o que deseja consultar. Feita esta indicação, o livro será enviado ao diretor do Arquivo, afim de que este designe o dia em que possa ser dada solução ao assunto, se não for possível fazê-lo imediatamente. ${ }^{14}$

E esse privilégio foi dado para poucos. Sousa, na condição de diretor, foi um dos que mais escreveram a partir dos documentos do arquivo, isto graças à monumentalização do arquivo através do preceito, exaurido nas primeiras décadas do século XX, de que o documento verdadeiro, meio para a prática historiadora, era, antes de tudo, um documento arquivístico.

Em 1936, Sousa, lançou o livro "História do Ceará para crianças (contada pelo rádio)", edição impressa dos resumos didáticos sobre a História do Ceará que ele, o "Vovô Ceará", personagem que assumira no programa da Ceará Rádio Clube, irradiava aos domingos para as crianças fortalezenses. $\mathrm{Na}$ justificativa da obra, se precaver das possíveis críticas (escrever para crianças não parecia uma prática comum entre os intelectuais) enaltecendo o uso exacerbado que fez de documentos (que ele bem os tinha por perto) e as letras históricas dos "heródotos cearenses", seus pares do Instituto do Ceará:

O que posso garantir é o seguinte: se de meus esforços não resultar um livro bom, útil, seguramente documentado, bem escrito e revelador do que a maioria dos filhos da malsinada terra das sêcas tanto necessita, pelo menos houve o meu ardente e justo anseio de assim fazê-lo. [...] não foram histórias do "arco da velha" para acalentar menino chorão... Foram fatos reais, positivos, através dos ensinamentos que nos deixaram os livros dos sabedores da história, os "herodotos cearenses" - aqueles que se têm ocupado da História do Ceará. ${ }^{15}$

\section{ARQUIVO, A CASA DO PASSADO E DO TRABALHO}

O Regulamento do Arquivo Público do Estado do Ceará data de 1932 e foi elaborado em decorrência do Decreto ${ }^{\circ} 479$, por ordem do Capitão Roberto Carneiro de Mendonça, interventor federal do Estado do Ceará, e teve a colaboração de Eusébio de Sousa. O documento é dividido em sete capítulos: natureza, fins e organização do arquivo público; aquisição, classificação e guarda de documentos; da consulta de documentos; pessoal do arquivo; das conferências; do museu histórico; disposições gerais. Este não foi o primeiro regulamento que teve o arquivo, mas se destaca por ter estabelecido seções por assunto/tema: seção administrativa, histórica, legislativa e judiciária. 
Ainda no século XIX, o arquivo, ora ligado mais aos negócios da secretaria de governo do presidente de província e ora à administração provincial como um todo, tivera diversos regulamentos e fora, a partir de 1865 , divido em seções semelhante às dos outros órgãos públicos que se estruturavam de acordo com as competências e pessoal da repartição, caso, por exemplo, da Tesouraria Provincial e da Instrução Pública.

Em data mais próxima àquela em que o arquivo foi dirigido por Sousa, 1916, tem-se referência acerca da feitura de Regulamento para o arquivo:

Pela lei n.1.371, de 6 de Setembro do anno passado, foi o Governo autorizado a remodelar a Bibliotheca e instituir o Archivo Publico, dando-lhe feição consentânea com os fins a que é destinado. Já se acha expedido o respectivo regulamento, no qual são atendidas as necessidades que esses institutos devem satisfazer. ${ }^{16}$

Contudo, o teor de originalidade e contundência do Regulamento de 1932, que justifica o estabelecimento das seções histórica, legislativa, judiciária e administrativa, como base classificatória para o recolhimento de documentos, dá-se sobremaneira pelo discurso conceitual arquivístico sobre "organização de arquivo" 17 , em diálogo com os demais documentos - o Decreto 479, 643, o Relatório de Atividades de 1932 e outros do "Grupo Arquivo Público e Museu" (Índice do APEC) - que referenciam o arquivo como "casa do passado". Com esta configuração o arquivo torna-se, portanto, uma espécie de lugar da produção "fabril" e de consumo dos documentos do arquivo e da história. Daí a necessidade de se fazer uma "justíssima homenagem" aos senhores colaboradores e fundadores do Instituto do Ceará, aos historiadores cearenses: Capistrano de Abreu, Tristão Araripe, Thomaz Pompeu, Antonio Bezerra e Paulino Nogueira, "batizando" as seções com os nomes de cada um deles. O arquivo como "mimo" do passado!

Oportuna foi a medida posta em prática por esta Diretoria dando designações especiais ás várias dependências do Arquivo Público no desdobramento de suas seções. [...] As quatro primeiras divisões receberam as seguintes denominações: Sala Tomaz Pompeu (seção administrativa); Sala Capistrano de Abreu (seção Histórica); Sala Paulino Nogueira (seção legislativa e judiciária); Sala Conselheiro Tristão Alencar Araripe (de consultas) e Sala Antonio Bezerra (Museu Histórico). É evidente o valor dos ilustres patronos das seções referidas, cearenses de incontestável projeção nos vários ramos do saber humano, cujo renome ultrapassou as nossas lindes, conhecidos como se tornaram em todo País, todos eles com pesada bagagem de trabalhos que atestam a sua ilustração. ${ }^{18}$ 
Sousa associava, assim, à ideia de arquivo público como entidade incumbida da guarda de documentos públicos que remeteriam tanto à história e à memória da organização do arquivo, ou mesmo às suas razões históricas, administrativas e arquivísticas, como ao discurso museográfico e museológico pautado nas práticas antiquárias e colecionistas, contexto bem mais familiar aos futuros consulentes do que as salas de um arquivo. A começar pela ornamentação da "sala da directoria":

Figura 3 - Arquivo Público do Estado do Ceará, em 1932

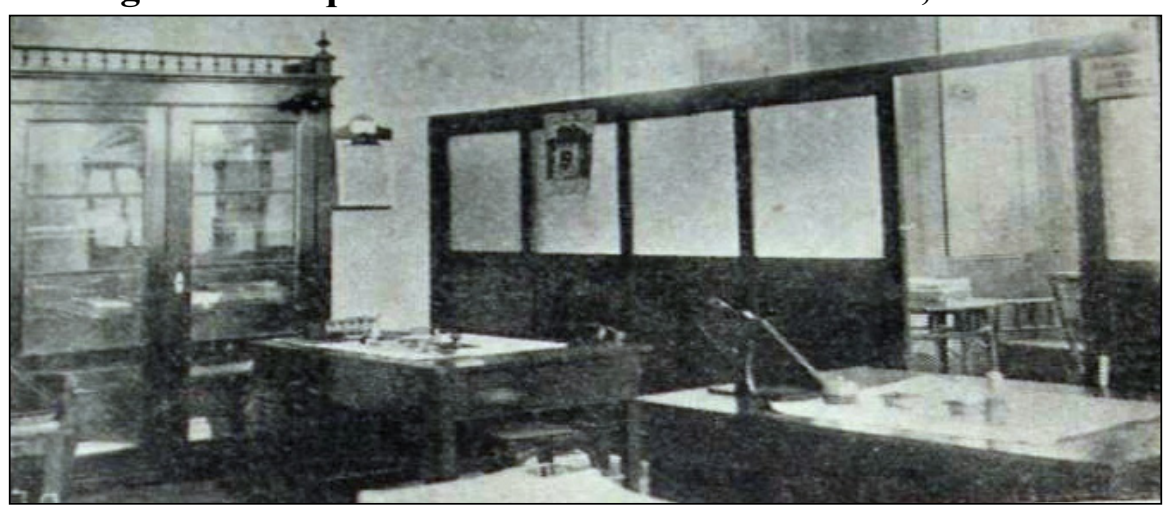

Térreo do Palácio da Luz (sede do governo estadual à época, localizado na conhecida Praça dos "Leões", centro de Fortaleza), que hoje abriga a Academia Cearense de Letras. Em foco: o "Salão da Directoria", sala de trabalho do diretor do arquivo, Eusébio de Sousa. Fonte: REPUBLICA DOS ESTADOS UNIDOS DO BRASIL, $1936 .{ }^{19}$

A sala da diretoria era a antessala e a "torre de controle" do arquivo (dos documentos, dos visitantes ou consulentes e dos funcionários), a porta de entrada e saída, literalmente, dos documentos para arquivamento nas respectivas seções ou para consulta.

Art.23. Nenhum documento, maço, caixa ou livro poderá sair de onde esteja; quer para o serviço das secções, quer para a sala de consultas, sem que no respectivo lugar, seja posto um cartão em que se declare o objeto dali tirado; o nome de quem o tirou e o visto do diretor. Êsse cartão será entregue ao diretor depois que o objeto fôr posto no seu lugar. ${ }^{20}$

As demais salas, como a da seção histórica, de consultas e do museu histórico (analisadas no item anterior), seguiam o mesmo padrão de arrumação e decoração da sala do diretor, condizente com a riqueza biobibliográfica dos homenageados, feita com objetos doados para o Museu Histórico e com o "mobiliário de arquivo", entre os quais: vaso para lixo, quartinhas, bandeira 
nacional, cadeiras de cipó, porta-chapéus, estantes, belchiores, escaninhos e uma máquina de escrever da marca "Remington".

Os objetos para a materialização e partição dos documentos no arquivo foram adquiridos em função dos "bons modos" necessários para dar efeito ao ajustamento da conduta arguida aos frequentadores (tanto os sócios do Instituto do Ceará como outros "curiosos" dos fatos históricos e dos poderes públicos e documentalistas principiantes) e empregados de um arquivo público, erigido sob legendas tão ilustradas.

Segundo o Regulamento do arquivo não seriam admitidas pessoas mal trajadas, danificar o mobiliário e os objetos consultados, “[...] apoiar-se sobre os livros, mapas, plantas, papeis e objetos; fazer-lhes marcas ou mossas com lápis, tinta, unha... anotá-los... perturbar o silêncio por meio de conversa ou leitura em voz alta [...]”. Já os funcionários não poderiam

levar para fora do arquivo livro de registro, maços de documentos, nem mesmo qualquer documento; não poderão também organizar, para si ou para outrem, coleção de assinaturas autografadas, de selos ou de qualquer peça do Arquivo. [...] serão demitidos os funcionários que revelarem o assunto de papeis reservados existentes no Arquivo, subtraírem ou extraviarem qualquer documento a este pertencente. ${ }^{21}$

Afinal, o que viria a ser uma "sala de consultas" ou "seções" de um arquivo? E que "modos" deveriam ter os homens no arquivo? Nesse sentido, me aproprio do pensamento de Gilberto Freyre acerca dos "modos de homens e modas de mulher" como elemento cultural na formação do comportamento social e de gênero do brasileiro, na parte em que o autor dá significado geral ao termo "tenha bons modos", um dos coloquialismos históricos oriundo dos estudos sociais dos anos 1930, que ditaram os entendimentos sobre ética e civilidade, principalmente dos homens, nos espaços públicos e privados:

São da linguagem cotidiana expressões como "homens de bons modos", "homem de modos finos", com "modos", nesses casos, e correspondendo àquelas maneiras, feições ou formas particulares e, até, jeitos, artes e comedimentos próprios de homens bem-educados. De homens habilidosos. De homens requintados nos seus comportamentos ou, particularmente, nos seus meios, civilizados e civilizantes, de expressão.

De onde as palavras módulo e modulação, a primeira significando medida reguladora de proporções de uma obra arquitetônica, a segunda, ato ou efeito de modular, isto é, de dizer, de tocar ou de cantar melodicamente. Disciplinas 
sistemáticas, ou estéticas, de fazer, de construir, de compor, de ordenar, de ligar, de unir por diferentes meios técnicos, artísticos, engenhosos, capazes dessas articulações. ${ }^{22}$

Pensando a partir da postura literária de pesquisadores como o historiador Tristão de Alencar Araripe ${ }^{23}$, eis duas hipóteses que deram sustentação ao fazer arquivístico de Sousa, diante do ensejo de ter que lidar com, o que interpreto como perspectiva antropométrica ou visão etnográfica do/no arquivo. ${ }^{24}$

$\mathrm{O}$ arquivo para torna-se uma bela casa do passado, com homens, documentos, salas, objetos e mobílias em harmonia, era preciso: primeiro, tornar o momento da consulta aos documentos, uma ocasião ao mesmo tempo solene e bravia, a exemplo das buscas/salvamentos de documentos que esses sujeitos costumavam fazer em arquivos "perdidos" pelo Ceará, em outros Estados e mundo afora; segundo, fazer com que o desenho arquitetônico do arquivo, com salas, vestíbulo, portaria, museu, corroborassem na manutenção da tradição arqueológica acerca da "verificação" dos documentos para a "sincera narração dos fatos", apenas consultando-os, devolvendo-os todos bem alinhados, sem adquiri-los, como e para o "mérito" do trabalho realizado.

A base para a organização e administração do arquivo estava centrada na classificação dos papéis por seções: administrativa, histórica, legislativa e judiciária, que correspondiam a setores legais dos poderes públicos e, à parte destes, nos documentos de história, designados como tal por emergência da narrativa histórica e, não necessariamente, pelas operações arquivísticas que tinham. Em alguns casos representativos (como o das cartas de sesmarias), a análise da espécie documental diplomática (disciplina existente desde o século XVII, anterior à ciência arquivística) tinha como critério de categorização:

Carta de sesmaria. Documento diplomático testemunhal comprobatório, descendente. Diploma passado por uma autoridade suprema ou delegada, em geral governadores e capitães-generais, quando possuir este direito fixado em regimento, para conceder datas de terra. Protocolo inicial: nome e titulação da autoridade. Texto: nome do interessado, medidas da data de terra e sua localização geográfica. Protocolo final: datas tópica e cronológica e as assinaturas. [...]

A espécie documental é a configuração que assume um documento de acordo com a disposição e a natureza das informações nele contidas. A espécie documental diplomática é a espécie documental que obedece a fórmulas convencionadas, em geral, estabelecidas pelo direito administrativo ou notarial. [...] A espécie é que identifica o veículo que serviu como base jurídica consensualmente válida para que o conteúdo do documento, correto em 
sua estrutura semântica, se tornasse legítimo, fidedigno, credível $[\ldots] . .^{25}$

Exemplo disso são as cartas de concessões de sesmarias que, de acordo com o Regulamento, deveriam ser arquivadas na seção administrativa e não na seção histórica, pois, no Arquivo Público do Estado esta documentação dizia mais sobre a história dos fatos/atos jurídicos, administrativos e notariais, uma vez que são documentos-testemunhos das origens da propriedade rural das terras cearenses, contendo dados para os estudos sobre as terras públicas, devolutas ou não.

A regra geral para o recolhimento era identificar a procedência e a pertinência dos documentos, como alude o "Dicionário Brasileiro de Terminologia Arquivística”, resguardadas as devidas especificidades da época, anos 1930, quanto aos processos de arquivamento:

Procedência. Termo em geral empregado para designar a origem mais imediata do arquivo, quando se trata de entrada de documentos efetuada por entidade diversa daquela que a gerou.

Princípio da Pertinência. Princípio segundo o qual os documentos deveriam ser reclassificados por assuntos sem ter em conta a proveniência e a classificação original. Também chamada de princípio temático. ${ }^{26}$

Esta base e regra constavam desde 1838 no Regulamento do Arquivo Público do Império, situado no Rio de Janeiro, tendo perdurado como direcionamento exclusivo até a reforma de 1975, ocorrida quase uma década após o final da direção do historiador José Honório Rodrigues, 1958-1963, à frente do então denominado Arquivo Nacional. Rodrigues questionou sobre as distinções entre documentos administrativos e históricos e a superposição da gestão do arquivo a do documento. ${ }^{27}$

O Regulamento $\mathrm{N}^{\circ} .2$ de 2 de janeiro de 1838 dava as seguintes instruções ao Arquivo Público do Império:

Art. $1^{\circ}$. OArchivo Publico fica provisoriamente estabelecido na Secretaria d'Estado dos Negocios do Imperio, debaixo da inspecção do Ministro e Secretario d'Estado da mesma Repartição. Art. $2^{\circ}$. Será o Archivo arranjado em huma parte das Casas da dita Secretaria, que mais proporção e commodidade tiver para esse fim, e nella se collocarão os armários e gavetas, que forem necessários para boa guarda, e acondicionamento dos papeis, que nelle se deverem guardar. Art. $3^{\circ}$ Os armários e gavetas serão distribuídos por três Secções, que há de ter o Archivo; a saber: Legislativa, Administrativa, e Histórica. ${ }^{28}$ 
O Manual da Associação dos Arquivistas Holandeses (1898), quando traduzido para o português e publicado no Brasil em 1960 (1 ${ }^{\circ}$ edição), fundamentou ainda a ordenação sistemática para os documentos dos arquivos.

O sistema de arranjo deve ser baseado na organização original do arquivo, a qual, na sua essência, corresponde à organização do órgão administrativo que o produziu. [...] Dois métodos se oferecem à nossa atenção. $\mathrm{O}$ primeiro adota vários cabeçalhos arbitrariamente determinados (por exemplo, Órgão administrativo, Finanças, Assistência, etc.), correspondentes aos que, via de regra, aparecem no catálogo da biblioteca. O outro sistema, ao contrário, não fixa cabeçalhos arbitrários, mas apenas os sugeridos pelo caráter e organização do próprio arquivo, a saber, os cabeçalhos condizentes com os vários ramos do órgão administrativo que produziu este último. ${ }^{29}$

\title{
OS DOCUMENTOS DO ARQUIVO ENTRE SEÇÕES E PRATELEIRAS
}

As estantes e prateleiras da secção administrativa do Arquivo Público do Ceará deveriam conter, entre outros, nove tipos documentais previamente determinados:

\begin{abstract}
II - as proclamações ou manifestos do poder executivo e cópias autenticas de iguais atos dos antigos Governadores e Presidentes da Província ou Estado; V - Os originais e registros das antigas cartas de concessões e confirmação de sesmarias; relações dos processos de mediação e demarcação dos terrenos devolutos que foram enviados pelas autoridades competentes; os documentos demonstrativos das vendas ou cessão dos mesmos terrenos, anteriores ao atual regimen, e cópia dos mesmos atos posteriores á promulgação da Constituição da República; VIII - Os originais da correspondência oficial dos antigos presidentes das províncias e dos secretários da Assembléa Provincial ou do Estado com os secretários de Estado, sobre assuntos de importância politica ou administrativa. ${ }^{30}$
\end{abstract}

Na seção administrativa estariam reunidos todos os registros documentais do recém Governo Estadual do Ceará, sistema representativo instaurado após a proclamação da República, em 1889. É muito evidente a preocupação com certas permanências do "antigo regimen" [sic], do governo provincial, como a 
recomendação expressa em obter "os originais dos contratos de empréstimos efetuados dentro ou fora da Província ou do Estado, [...] os originais dos documentos que demonstrarem a propriedade dos bens provinciais e estaduais".

Os documentos da secretaria da administração provincial eram descritos e contabilizados por sua espécie (ofícios, certidões etc.) e natureza do assunto (sigilosos ou ostensivos), e não pelos propósitos do conteúdo, ou através do registro, em livros, por cópia ou lista numérica de todos os papéis recebidos e expedidos pela secretaria e inventariado pelo arquivo da secretaria do governo da província.

Contudo, a leitura do pessoal do "novo" arquivo denota aos documentos da administração provincial e estadual sua condição de prova históricoadministrativa, dos feitos e mandos ocorridos no tempo passado, pois, o regulamento do arquivo e os serviços realizados na seção administrativa não produziriam, arquivariam prova contra ou à revelia deles mesmos (do interventor federal, do governador e dos funcionários do arquivo), ou seja, não tratavam mais os documentos ditos administrativos pelo seu valor de prova ou informação a ser repassada ao Governo Geral (poder moderador e executivo da Corte no Rio de Janeiro) ou à administração provincial. De fato, esses documentos serviram ao seu momento e no tempo presente-passado, à história administrativa provincial, como se tivessem sido, nos termos de hoje, ultrapassadas as três idades do arquivo (corrente, intermediária e permanente) no governo de um único presidente de província.

E, tratando-se dos negócios territoriais ("antigas cartas de concessões e confirmação de sesmarias”), empréstimos e bens, os manuscritos do século XIX serviam ao governo e ao governador do Estado do Ceará como testamento, garantindo-lhe direito de uso e posse.

Diferentemente dos arquivos provinciais, que não timbravam os documentos recolhidos, coube ao arquivo público colocar a chancela, o selo "arquivo público", definindo o lugar ao qual "pertenciam” os documentos. 
Figuras 4 e 5 - Imagens da chancela do Arquivo Público do Estado do Ceará

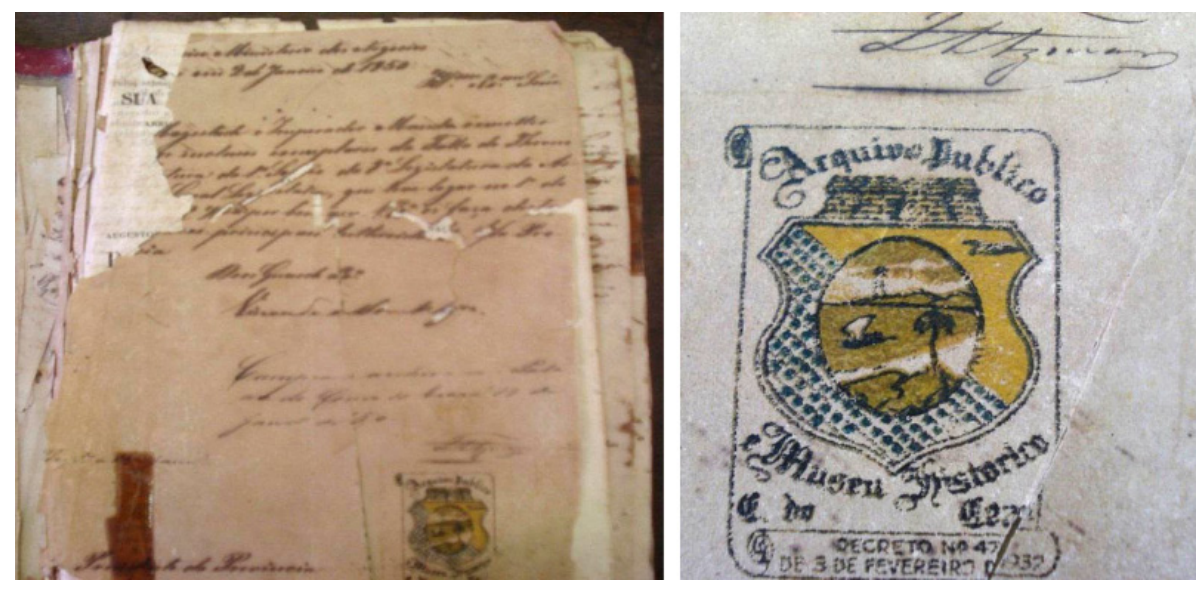

A marca foi instituída em 1932 como elemento definidor do recolhimento e da custódia do acervo, caso do Aviso do Ministério do Império enviado ao Presidente da Província do Ceará em 2 de janeiro de 1850. Fonte: APEC, $1850 .{ }^{31}$

$\mathrm{Na}$ seção histórica seriam arquivados documentos sobre a divisão eclesiástica da "antiga" província, relatórios "de qualquer gênero" do Governo do Ceará (incluindo os presidentes do Estado ou do governador das três primeiras décadas do regime republicano, o governo provisório - 1930 e 1931 - e o governo em curso dos interventores federais) e

I - Os originais e cópias autenticas de todos os documentos relativos á Independencia do Brasil que se relacionem com o Estado do Ceará e que não tiveram classificação especial. II - Os originais e cópias autenticas de todos os documentos relativos á Proclamação da República, que se relacionem com o Estado do Ceará e dos de adesão desse mesmo Estado a essa forma de governo; e quaisquer documentos relativos ao governo provisório do Ceará; III - Os documentos e papeis que não devem ter classificação especial relativos a movimentos políticos na antiga Provincia ou Estado. [...] VIII - Registro de correspondência e de atos dos antigos governadores da capitania e de toda correspondência que se relacionar com os mesmos. [...] X - Os originais e cópias autenticas da correspondência do Governo com a União, com o de outras quaisquer Provincias ou Estados, sobre negocios importantes e findos, mas que devem ser conservados no Arquivo para auxilio histórico. [...] XII Todos os documentos, memoriais, relatorios, roteiros ou noticias relativos á geografia e história do Ceará $\left[\ldots . .{ }^{32}\right.$ 
O Arquivo Público do Ceará, com a definição dos documentos que iriam compor a seção histórica, instaurava um saber arquivístico e histórico que nortearia o ensino de história nas escolas (vai se formando uma concepção não teológica do mundo e da história), a percepção sobre o que era ou não histórico, e daria legitimidade aos pensamentos dos intelectuais do Instituto do Ceará, uma vez que estes criavam textos, narrativas históricas contemplando e sacralizando a história oficial do governo soberano e a história do Ceará, interiorizada e coadjuvante.

O conhecimento histórico não parte de uma revelação "divina" ou aleatória, mas de uma explicação da razão, que passa pelo método arquivístico. É o racionalismo que se impusera em prol do progresso e a da perfeição do mundo real, do estado real, experimentado, vivido e percebido.

Com a preocupação com os textos antigos e com a exatidão, através da pesquisa e a formação de coleções de moedas, de objetos de arte, de inscrições antigas, levanta-se um enorme manancial para a reconstituição do passado. Do século XVI ao XIX, foram multiplicadas as técnicas para reunir, preparar e criticar toda essa documentação, que fornece os dados e os elementos para a interpretação histórica. Esse conjunto de técnicas e lugares de aplicação e adaptação destas técnicas se aperfeiçoou constantemente nesse período - os anos 1930-1940 - em todo Brasil e veio auxiliar o estudo da História nas universidades e institutos históricos. Seu conjunto construiu a erudição histórica.

Do avanço dessas técnicas eruditas é que ressurgirm as chamadas "ciências auxiliares ou afins da História", tais como a cronologia, a epigrafia, a numismática, a sigilografia, a onomástica, a heráldica, a genealogia, a arqueologia, a filologia e, em especial, a diplomática e a paleografia.

Dos documentos do poder legislativo e do judiciário, ao arquivo caberiam, respectivamente, por exemplo:

I - Os originais da Constituição Política do Estado, de 23 de dezembro de 1890; idem, de 16 de junho de 1891; idem de 12 de julho de 1892; idem da Reforma da Constituição Politica do Estado de 19 de junho de 1905; idem, das Constituições Políticas do Estado de 4 de novembro de 1921 e 24 de setembro de 1925. [...]

III - Todos os autos, livros e papeis de cartorios do Estado, de mais de 30 anos, contados da data do ultimo ato neles lançados. ${ }^{33}$

Por que poderiam ser arquivados os documentos findos de cartórios, passados 30 anos? Por que 30 anos e não 20, ou menos ou mais? Essa era uma "tabela de temporalidade" adotada e estabelecida em outros arquivos? Ou uma invenção arquivística do Ceará? 
Ao que parece, este tipo de "norma decanato" é dada também de forma arbitrária e autoritária em outros estados e municípios, como no Arquivo Histórico de São Paulo, criado como arquivo da Secretaria Geral do município de São Paulo, em 1899.

Cumpre notar que na ótica do ato de 1936 (artigo 217, parágrafo único), o "papel e documento histórico ou antigo é todo aquele existente no Arquivo Municipal há mais de 30 anos". Definição que explica o fato de durante muito tempo a maior parte da documentação histórica acumulada no AHSP não haver ultrapassado o limiar do ano de $1906 .^{34}$

O tempo, a temporalidade em arquivos, é a dimensão da análise básica da pesquisa histórica, contudo, o tempo histórico através do qual se analisam os acontecimentos não corresponde ao tempo cronológico que é definido pelos relógios, calendários e arquivos. O tempo sempre se constitui em uma preocupação do homem público, desde épocas remotas, e a necessidade de se estruturar a vida da instituição e dos seus congêneres através de uma melhor distribuição de tempo. Isto se deve ao fato de ser o homem um ser finito, temporal e histórico. Ele tem consciência de sua historicidade, isto é, de seu caráter eminentemente histórico.

Ao estipular prazo legal de 30 anos - sem explicação arquivística plausível ou lógica diante dos critérios para os outros conjuntos documentais para o arquivamento em arquivo público dos autos, livros e papéis dos cartórios, o arquivo infere uma periodização, organiza a sucessão de diferentes períodos cronológicos e "desvaloriza" os documentos cartorários, de fé pública. Este tratamento fez com que a historiografia renegasse até recentemente esses documentos, que não eram tidos como fontes históricas. À exceção dos que se prestariam às genealogias e biografias de pessoas e famílias de destaque político, econômico e intelectual.

$\mathrm{O}$ alinhamento dos documentos do arquivo em inúmeras prateleiras (mobiliário da memória) bem postas nas tais seções, ainda que fossem prateleiras primitivas, antiestéticas e frágeis, enchiam os olhos do diretor do arquivo que, aos poucos, percebia o preenchimento das lacunas da história, em especial com o empilhamento de documentos remanescentes da história do Ceará. Assim, tinha fácil o arsenal completo para proferir, ele, ou os funcionários do arquivo ou pessoas convidadas, cursos e conferências acerca dessa disciplina.

Art. 56- Cursos especiais e conferências avulsas sobre assuntos históricos poderão realizar-se por iniciativa do diretor ou mediante a sua permissão. O diretor terá, sempre, o direito de exigir que lhe seja apresentada, com 
a devida antecedência, a conferência escrita, para depois de lê-la autorizar ou não a sua realização. [...] Art.57- O arquivo procurará relembrar as grandes datas cearenses, por meio de exposições especiais ou por outras formas de comemoração. ${ }^{35}$

Os discursos legais de ordenamento do arquivo, por essa chave de leitura, perpassam os caminhos da teoria literária e da escrita da história, como suscita Hayden White ${ }^{36}$, no momento em que o texto jurídico-administrativo se faz a partir da coexistência com práticas arquivísticas passadas, mas leva a crer que essa escrita é mais uma crônica que dará lugar à história factual. O arquivo, ao produzir provas sobre ele mesmo, vai se tornando o referencial de escrita, a "letra redonda" ${ }^{37}$, como era definida pelos leitores, os "typos", a letra dos jornais cearenses no século XIX. Prova de que os elementos linguísticos, históricos e sociais só fazem sentido juntos e na experimentação do (re) conhecimento do trabalho da criação linguística e da semiótica na composição do texto historiográfico sobre a história e a memória do fazer arquivístico.

A história de vida do Arquivo, dos fatos e acontecimentos que o ergueram, é cara aos historiadores, porque é preciso fazer ponderações acerca dos significados literários e da atuação da memória, remetendo-se à história como algo plural e humano, que ganha corpo na narrativa ao incluir componentes de retórica, estilo e imaginação literária.

Agrega aos seus depoimentos os historiadores, leitores do arquivo, as coletividades das impressões de antecessores, dos sucessores e do público, de modo geral, já que assim imagina ficar mais fácil reconhecer a função sócio-histórica das suas recordações. E aí se insinua a prosa com White, que, ao reportar-se à historiografia, afirma que o discurso é uma representação do imaginário no qual seu autor está inserido. O historiador, portanto, não é o único responsável pelos significados que existem no seu discurso com base nos documentos de arquivo, mas também o são os gestos alheios inerentes ao fazer arquivístico, visto que todos estes fazem parte da memória coletiva.

Ou seja, a lógica do discurso histórico, a retórica, advém de palavras e lugares que historicamente tornam-se conceitos. O arquivo, para Eusébio Sousa, por exemplo, significou enredo e verdade, simbolizando para seus conhecedores vestígios de história e memória.

\section{NOTAS}

1 Este artigo, com algumas alterações, representa o capítulo 1 da minha tese de doutorado defendida em junho de 2012 no Programa de Pós-Graduação em História da Universidade do Vale do Rio dos Sinos (PPGH-UNISINOS)/ Rio Grande do Sul, sob orientação do Prof. Dr. Paulo Roberto Staudt Moreira. A tese intitula-se: “Archive-se!' História, Documentos e Memória Arquivística no Ceará (1835-1934). 
2 SOUSA, Eusébio. Relatório apresentado ao Exmo. Sr. Secretário dos Negócios do Interior e da Justiça do Estado pelo Diretor do Arquivo Público, referente ao período de 7 de junho a 31 de dezembro de 1932. Fortaleza, (s.n.), 15 fev. 1933, p. 2.

3 Ao longo desse texto fornecerei, a partir do estudo sobre o arquivo, mais dados sobre a biografia de Eusébio Néri Alves de Sousa, Eusébio de Sousa. Contudo, seguem algumas notas iniciais: Eusébio de Sousa foi advogado, juiz, jornalista e historiador, nasceu em Recife em 1883 e faleceu em 1947 com 64 anos, residindo em Fortaleza. Diretor do Arquivo Público e Museu Histórico do Estado do Ceará, entre 1932 e 1942. Em 1942, aposenta-se do serviço público. Fontes: HOLANDA, Cristina Rodrigues. Museu Histórico do Ceará: a memória dos objetos na construção da História (1932-1942). Fortaleza: Museu do Ceará/Secretaria da Cultura do Estado do Ceará, 2005. p.17-18. Segue referência ao ofício que trata do ato de nomeação de Sousa como diretor do Arquivo em 01 de junho de 1932, iniciando os trabalhos dia 7 de junho de 1932: Arquivo Público do Estado do Ceará-APEC. Cópia dos Ofícios expedidos por esta Repartição durante o ano de 1932. Ofício n ${ }^{\circ}$.1. Expedido por Eusébio de Sousa para o Olívio Dornelas Câmara, Secretário dos Negócios do Interior e Justiça, em 07 de junho de 1932.

${ }^{4}$ NORA, Pierre. Entre história e memória. A problemática dos lugares. Revista Projeto História, São Paulo, PUC, n.10, p. 07-28, dez. 1993, p. 14; RICOUER, Paul. A memória, a história e o esquecimento. Campinas: Editora da UNICAMP, 2007. p. 414.

${ }^{5}$ SOUSA, op. cit., p. 44.

${ }^{6}$ REPUBLICA DOS ESTADOS UNIDOS DO BRASIL. ESTADO DO CEARÁ. Relatório apresentado ao Exmo. Snr. Presidente da República pelo Interventor Federal Cap. Roberto Carneiro de Mendonça. 22 de setembro de 1931 a 5 de setembro de 1934. Fortaleza: Imprensa Official, 1936, p. 54.

7 REPUBLICA DOS ESTADOS UNIDOS DO BRASIL. ESTADO DO CEARÁ. Relatório apresentado ao Exmo. Snr. Presidente da República pelo Interventor Federal Cap. Roberto Carneiro de Mendonça. 22 de setembro de 1931 a 5 de setembro de 1934. Fortaleza: Imprensa Official, 1936, p. 57.

8 APEC. FUNDO: Interior e Justiça. Série: Arquivo Público, Biblioteca Pública e Museu Histórico do Ceará. Data-limite: 1878-1944. Esta série é composta por livros de registros de leitores da Biblioteca Pública do Ceará, entre 1878-1887 e 1894-1896; livros de ponto e livros de assinaturas de visitantes do Museu Histórico do Ceará e do Arquivo Público do Estado do Ceará, de 1932-1944. Não conta nesta série, documentação referente ao arquivo no governo da província do Ceará, século XIX. APEC. Índice de localização do grupo arquivo público e museu histórico. Data Crônica: 1932-1958. Ala 03, Estante 04.

9 NORA, Pierre. Op. cit., p. 15-16. O estudo a contrapelo acerca dos processos de acumulação e arquivamento dos "registros de si" do arquivo faz alusão ao que Nora chama de "materialização da memória" e "vontade geral de registro" e ao fato de que os historiadores precisam analisar $\mathrm{o}$ arquivo como lugar de memória, bem como, a memória do lugar.

${ }^{10}$ SCHELLENBERG, Theodore R. Arquivos Modernos: princípios e técnicas. Rio de Janeiro: Ed. FGV, 2006. p. 35.

${ }^{11}$ NORA, op. cit., p. 14.

${ }^{12}$ Anais do Arquivo Público do Estado do Ceará. Tomo I. Ano I. Fortaleza: Oficinas gráficas da Cadeia Pública, 1933. Publicação integrante de: APEC (org.). Datas de Sesmarias do Ceará e indices das datas de sesmarias: digitalização dos volumes editados nos anos de 1920 a 1928. Fortaleza: Expressão Gráfica/Wave Media, 2006. 2 CD-ROOM. (Coleção Manuscritos/ Arquivo Público do Ceará, v.03). APEC. Índice de localização do Grupo Arquivo Público e 
Museu Histórico. Data Crônica 1932-1958. Série: Catálogo Geral do Acervo. Ala 03, Estante 04, Caixa 06, Livro 21, Prateleira 22. Data Crônica: 1934.

${ }^{13}$ SOBRINHO, Thomaz Pompeu. Tapuias do Nordeste. Revista do Instituto do Ceará. Ano LIII, Fortaleza, Tomo LIII, 1939, p. 221 e 222; . Pré-História Cearense. História do Ceará. Monografia n. 3. (1 Tomo). Fortaleza: Editora do Instituto do Ceará, 1955.

${ }^{14}$ SECRETARIA DOS NEGÓCIOS DO INTERIOR E DA JUSTIÇA DO ESTADO DO CEARÁ. Regulamento do Arquivo Público do Estado do Ceará. Aprovado pelo Decreto N. 643, de 20 de Junho de 1932. Fortaleza: Tip. Cadeia, 1933, p. 12-13.

${ }^{15}$ SOUSA, Eusébio. História do Ceará para crianças (contada pelo rádio). Fortaleza: [s.n], 1936.

${ }^{16}$ Mensagem apresentada à Assembleia Legislativa do Ceará, em 1 de Julho de 1917 pelo Dr. João Tomé de Saboya e Silva, presidente do estado do Ceará. Disponível em: <www.crl. edu>. Acesso em: 08 dez. 2011. O Regulamento ao qual se refere o presidente de Estado não foi localizado no acervo do APEC.

${ }^{17}$ SCHELLENBERG, Theodore. Manual de arquivos. Rio de Janeiro: Ministério da Justiça/ Arquivo Nacional, 1959. p. 17-18.

${ }^{18}$ SOUSA, 1933, op. cit., p. 45.

${ }^{19}$ REPUBLICA DOS ESTADOS UNIDOS DO BRASIL. ESTADO DO CEARÁ. Relatório apresentado ao Exmo. Snr. Presidente da República pelo Interventor Federal Cap. Roberto Carneiro de Mendonça. 22 de setembro de 1931 a 5 de setembro de 1934. Fortaleza: Imprensa Official, 1936, p. 54.

${ }^{20}$ SECRETARIA DOS NEGÓCIOS DO INTERIOR E DA JUSTIÇA DO ESTADO DO CEARÁ. op. cit., p. 12.

${ }^{21}$ SECRETARIA DOS NEGÓCIOS DO INTERIOR E DA JUSTIÇA DO ESTADO DO CEARÁ. op. cit., p. 13-17.

22 FREYRE, Gilberto [1986]. Modos de homem e modas de mulher. Rio de Janeiro: Record, 1997, p. 12.

${ }^{23}$ ARARIPE, Tristão de Alencar (1821-1908). História da Província do Ceará. (Dos tempos primitivos até 1850). Fortaleza: Edições Fundação Demócrito Rocha, 2002. A primeira edição desse livro data de 1867.

${ }^{24}$ CUNHA, Olívia Maria Gomes da. Do ponto de vista de quem? Diálogos, olhares e etnografias dos/nos arquivos. Revista Estudos Históricos. Antropologia e Arquivos. Rio de Janeiro, n.36, jul./dez. 2005, p.7-32.

${ }^{25}$ BELLOTTO, Heloísa Liberalli. Diplomática e tipologia documental em arquivos. Brasília: Briquet de Lemos Livros, 2008. p. 31 e 41.

${ }^{26}$ ARQUIVO NACIONAL (BRASIL). Dicionário Brasileiro de Terminologia Arquivística. Rio de Janeiro: Arquivo Nacional, 2005. p. 136-137.

${ }^{27}$ Cf. HEYNEMANN, Cláudia. Arquivo Nacional. Rio de Janeiro: Arquivo Nacional, 2004, p. 41. "O regimento aprovado em 1975 deu um passo importante, ao incorporar, decididamente, a ideia de gestão de documentos, por meio da Divisão de Pré-Arquivo, que no ano seguinte se instala também em Brasília, demonstrando a preocupação do Arquivo em atuar junto à administração pública da capital [...]”.

${ }^{28}$ COLLECÇÃO DAS LEIS DO IMPÉRIO DO BRASIL. 1838. Tomo I. Parte II. Rio de 
Janeiro: Typographia Nacional, 1839, p.9. Disponível em: <http://www2.camara.gov.br/ atividade-legislativa/legislacao/publicacoes/doimperio>. Acesso em: 31 jan. 2012.

${ }^{29}$ ARQUIVO NACIONAL, Ministério da Justiça. Manual de Arranjo e Descrição de Arquivos. Arquivo Nacional. Preparado pela Associação dos arquivistas Holandeses. Tradução de Manoel Adolpho Wanderley. 2 ed. Rio de Janeiro: 1973, p. 44.

${ }^{30}$ SECRETARIA DOS NEGÓCIOS DO INTERIOR E DA JUSTIÇA DO ESTADO DO CEARÁ. op. cit., p. 4-5.

${ }^{31}$ APEC. Índice de localização do Fundo Ministérios. Data Crônica: 1822-1909. Ala 04, Estante 05, Prateleira 23. Livro 04. Avisos do Ministério do Império ao Presidente da Província do Ceará. 1850-1852. Rio de Janeiro, 2 de janeiro de 1850.

${ }^{32}$ Ibidem, p. 5-6.

${ }^{33}$ Ibidem, p. 7-8.

${ }^{34}$ Disponível em: < http://www.prefeitura.sp.gov.br/cidade/secretarias/cultura/arquivo_ historico/arquivo_historico/index.php?p=1114>. Acesso em: 31 jan. 2012.

${ }^{35}$ SECRETARIA... op. cit., p. 22.

${ }^{36}$ WHITE, Hayden. Trópicos do discurso: ensaios sobre a crítica da cultura. São Paulo: Ed. USP, 2001.

${ }^{37}$ No final do século XIX, o jornal conservador Constituição publicou informação errada com relação à data de realização do Santo Sepulcro em Fortaleza - CE. Os leitores, através de cartas enviadas ao periódico opositor, o Cearense, enfatizam que não se tratava de equívoco, pois a letra redonda, ou seja, as letras da imprensa, os typos, não mentiriam. (Fortaleza CE. Cearense, 19/03/1880). A "letra redonda" deve ser aqui compreendida como o registro arquivístico que é impresso, publicado em livro e sujeita a interpretações. Cf. FERNANDES, Ana Carla Sabino. A imprensa em pauta. Jornais Pedro II, Cearense e Constituição. Fortaleza: Museu do Ceará/Secretaria de Cultura do Estado do Ceará, 2006.

Artigo recebido em maio de 2014. Aceito em agosto de 2014. 